ALI TAVAKOLI KASHANI, Ph.D. Candidate

E-mail: a tavakoli@iust.ac.ir

AFSHIN SHARIAT-MOHAYMANY, Ph.D.

E-mail: shariat@iust.ac.ir

ANDISHE RANJBARI, M.Sc. Student

E-mail: a_ranjbari@civileng.iust.ac.ir

Iran University of Science and Technology,

School of Civil Engineering

Narmak, Tehran, Iran
Preliminary Communication

Safety and Security of Traffic

Accepted: Nov. 2, 2009

Approved: Dec. 21, 2010

\title{
A DATA MINING APPROACH TO IDENTIFY KEY FACTORS OF TRAFFIC INJURY SEVERITY
}

\begin{abstract}
Seventy percent of the traffic crash fatalities of Iran happen on rural roads, and a significant proportion of the rural roads network of this country is constituted of the main twolane, two-way roads. The purpose of this study is to identify the most important factors which affect injury severity of drivers involved in traffic crashes on these roads, so that by eliminating or controlling such factors an overall safety improvement can be accomplished. Using the Classification and Regression Tree (CART), one of the powerful data mining tools, the crash data pertaining to the last three years (2006-2008) were analyzed. The variable selection procedure was carried out on the basis of Variable Importance Measure (VIM) which is one of the CART method outputs. The results revealed that not using the seat belt, improper overtaking and speeding are the most important factors associated with injury severity.
\end{abstract}

\section{KEYWORDS}

injury severity; traffic safety; data mining; Classification and Regression Trees (CART); Variable Importance Measure (VIM)

\section{INTRODUCTION}

Iran is one of the countries with a high rate of traffic crash fatalities and injuries. Over the last three years, traffic crashes in Iran resulted in 24,000 people (i.e. 3 persons per hour) on the average killed and around 240,000 injured annually [1].

Understanding the circumstances under which the drivers and passengers are more likely to be killed or more severely injured in an automobile crash is of special concern to researchers in traffic safety. Identification of these factors can help improve the overall driving safety situation, not only by preventing accidents but also by reducing their severity.
Seventy percent of the aforesaid fatalities happen on rural roads and thirty percent on urban roads. In addition to this, more than 90 percent of passenger carriage in Iran is carried out by road transportation mode [2], and a significant proportion of the rural roads network of Iran consists of two-lane, two-way roads.

The objective of this study is to identify the significant factors which affect injury severity of vehicle drivers involved in traffic crashes on two-lane two-way rural roads of Iran. Many of the previous studies in this domain have used regression type generalized linear models where the functional relationships between the injury severity and the crash-related factors are assumed to be linear. However, as noted by Mussone, Ferrari et al. [3], this assumption can lead to erroneous estimations of the likelihood of injury severity.

The Classification and Regression Tree (CART), an important data mining technique, is a non-parametric model without any pre-defined underlying relationship between the dependent and independent variables, which has been widely employed in many fields of study.

According to Han and Kamber [4], data mining is discovering and analyzing a large amount of data to find meaningful models and patterns. Considering the large amount of crash data on rural roads in Iran, CART was found to be a suitable approach for this study.

Breiman [5] devised a Variable Importance Measure (VIM) for trees, which may be applied as a criterion to select a subset of variables that have a major importance in predicting the target variable. The results can be put forth for other modelling tools, such as neural network.

In this study, significant factors influencing injury severity are identified using the variable importance measure (VIM) based on the classification tree.

The paper begins with a brief review of previous researches on modelling injury severity of traffic crashes 
and then presents the methodological approach. This is followed by the description of the data compilation and definition of all the variables. Then, analysis results will be given, along with the discussion of the findings. Finally, the last section summarizes and concludes the paper.

\section{LITERATURE REVIEW}

A considerable amount of studies have been carried out so far, to identify the factors most important in increasing or reducing the levels of injury or crash severity. The objective is to reduce the number of people killed and/or injured in traffic crashes, by help of elimination or control of these factors.

Most studies done in this field employed the logistic regression models to develop the severity of crashes or severity of crash-related injury prediction models. Singleton, Qin et al. [6] performed a logistic regression of injury severity to investigate factors associated with higher levels of injury severity in crashes where the occupant's vehicle was severely damaged. Analyzing traffic crash data in Kentucky 2000-2001, they concluded that the Occupant risk factors for higher levels of injury severity selected by the regression were age, female gender, restraint non-use, ejection from the vehicle, and driver impairment (by alcohol and/or drugs). Dissanayake and Lu [7] used logistic regression to identify factors influencing severity of injury to older drivers in fixed object-passenger car crashes. In another study, conducted in Saudi Arabia, a logistic regression approach was employed to examine the contribution of individual variables to the injury severity [8]. The results suggested that the location and the cause of crash are important factors in the increase of crash severity. Another logistic regression model was applied to quantify the association of driver's age with traffic injury severity [9]. They used Wisconsin Crash data from 2002 to 2004 to study 602,964 drivers involved in a motor vehicle crash, and found that the oldest drivers - especially those older than 85 years had the highest risk for severe injury and fatality.

Ordered probits are another group of models that have become popular in the crash severity modelling. For instance, an ordered probit model was employed at the University of Texas [10] in order to examine the risk of different injury levels. The results indicate that pickups and SUVs are less safe than passenger cars under single-vehicle crash conditions. However, in twovehicle crashes, they were found to be safer for their drivers and more dangerous for the occupants of their collision partners.

In recent years, using non-parametric and data mining methods, has increased significantly, and many researchers tried to apply these techniques in road safety analysis.
Among the data mining techniques, decision trees and rule, non-linear regression and classification methods, and neural network have been the popular data mining techniques.

Abdelwahab and Abdel-Aty [11] employed artificial neural networks to model the relationship between driver injury severity and the number of crash factors. A similar study conducted by Delen, Sharda et al. [12] used a series of artificial neural networks to model the potentially non-linear relationships between the injury severity levels and crash-related factors.

Chang and Wang [13] developed the CART model to establish the relationship between injury severity and driver/vehicle characteristics, highway/environmental variables and crash variables. By using 2001 crash data for Taipei, Taiwan, they concluded that the most important variable associated with crash severity is the vehicle type. Yan and Radwan [14] applied the classification tree method combined with the Quasiinduced exposure concept to perform an analysis on relation between rear-end crashes occurring at signalized intersections and a series of potential traffic risk factors. Analyzing 2001 Florida crash database, they found that rear-end crashes are over-presented in the higher speed limits (45-55 $\mathrm{mph}$ ), and the rearend crash propensity is larger for daytime, wet and slippery road surface conditions, male gender, and drivers younger than 21 years of age. Pande and Abdel-Aty [15] in another study employed classification tree based variable selection procedure to identify the important parameters leading to lane-change related freeway crashes, using the traffic surveillance data collected from a pair of dual loop detectors.

However, most of these previous studies focused on a few risk factors, some specific road users or certain types of crashes; and so the important factors affecting injury or crash severity have not been yet completely recognized. This gave us the reason to conduct this research. Besides, this study is distinctive from previous works, because of its significance in Iran (due to the high proportion of road transportation in passenger carriage), and the geographical vastness of data being analyzed throughout the study, that covers all the drivers involved in all the two-lane two-way rural roads of Iran, over the last 3 years.

\section{METHODOLOGY}

Variable importance measure (VIM) is one of the CART method outputs, on the basis of which variable selection procedure can be carried out.

Classification And Regression Tree (CART) is one of the most important and popular data mining tools, which turned out to be a powerful method for dealing with prediction and classification problems, particularly when there is a large amount of data with many independent variables. 


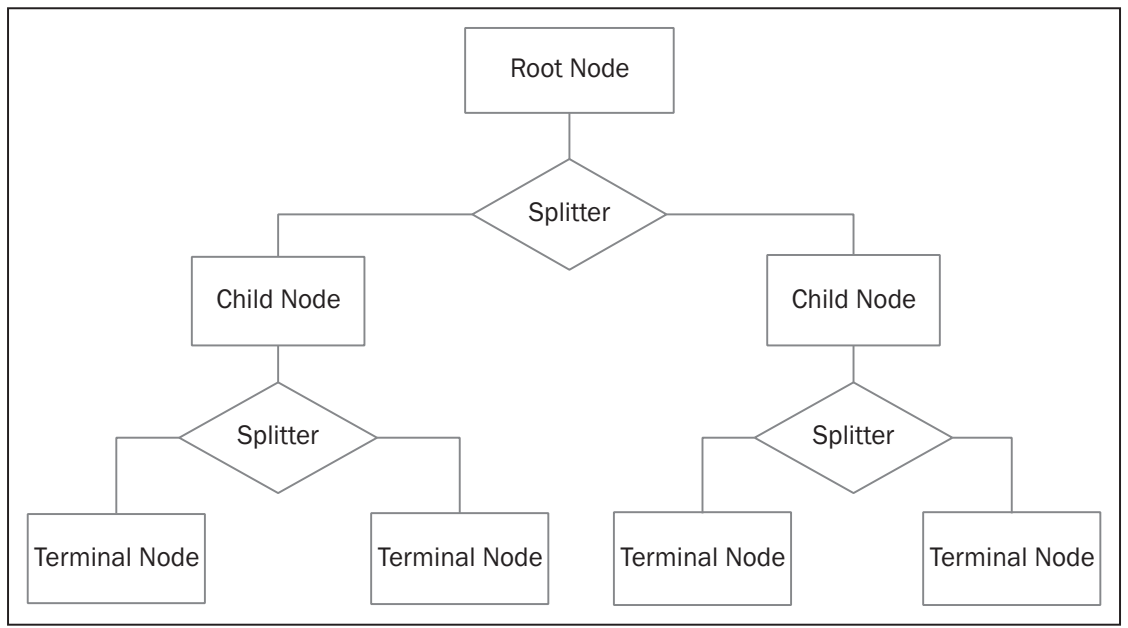

Figure 1 - General structure of a decision tree

Classification models are generated on the basis of the training data whose independent variables and target variables are known, to be applied for the new dataset whose objective is the prediction of the target variable.

The principle of CART method in developing the classification tree is described in the following: at first all data are concentrated at the root node, situated at the top of the tree. Further, it will be divided into 2 child nodes, on the basis of an independent variable (splitter), which create the best purity. In fact the data in each child node is more homogenous than its upper parent node. This process will be continued recursively for each child node, until all the data in each node have the most possible homogeneity. Such node is called terminal node or "leaf", and has no branches.

One of the most commonly applied criteria for splitting the classification tree is the Gini index, shown as follows [4]:

$$
\begin{aligned}
& \begin{array}{l}
p(j \mid m)=\frac{p(j, m)}{p(m)}, p(j, m)=\frac{\pi(j) N_{j}(m)}{N_{j}}, p(m)= \\
=\sum_{j=1}^{J} p(j, m)
\end{array} \\
& \operatorname{Gini}(m)=1-\sum_{j=1}^{j} p^{2}(j \mid m)
\end{aligned}
$$

where $J$ is the number of target variables or classes, $\pi(j)$ is the prior probability for class $j, N_{j}(m)$ is the number of records in class $j$ of node $m, N_{j}$ is the number of records of class $j$ in the root node, $p(j \mid m)$ is the probability of a record being in class $j$ provided that it exists in node $m$, and $\operatorname{Gini}(m)$ is an indication of impurity in node $m$. The Gini index equals 0 when all the observations in one node belong to a unique group (which shows the least impurity), and equals 1 when there are observations of different groups with the same proportion in one node. The prior probability shows the proportion of observations in each class in the dataset.
In the classification tree with $T$ total nodes, let $S\left(x_{j}, k\right)$ be the split at the $k^{\text {th }}$ internal node using variable $x_{j}$. The VIM for this variable is the weighted average of the reduction in the Gini impurity measure achieved by all splits using variable $x_{j}$ across all internal nodes of the tree, and the weight is the node size. If $N$ is the total number of observations in the training sample, then the formula for the importance for variable $x_{j}$ is given by the following [15]:

$\operatorname{VIM}\left(x_{j}\right)=\sum_{t=1}^{T} \frac{n_{t}}{N} \Delta \operatorname{Gini}\left(S\left(x_{j}, t\right)\right)$

where $\Delta \operatorname{Gini}\left(S\left(x_{j}, t\right)\right)$ represents the reduction of Gini index on the basis of variable $x_{j}$ in node $t$, and $n_{t} / N$ represents the proportion of the observations in the dataset that belongs to node $t$.

In this study, however, the VIM is computed for all the independent variables and is scaled in such a way that its summation for all the variables will equal 1. The variable that has the most importance with respect to others gets relatively the largest number.

\section{DATA DESCRIPTION}

The crash data from the records of the Information and Technology Department of the Iranian Traffic Police from 2006 to 2008 was used to study hundreds of drivers who were involved in traffic crashes on the main two-lane two-way rural roads of Iran. These data are obtained from the Iranian traffic crash record form, KAM 114, which contains the important information about the crashes, presented in Table 1.

Of the 14 variables presented in the table, injury severity is the target (dependent) variable -which has 3 levels of no-injury, injury and fatality- and the other 13 variables are the predictors.

According to the dataset there were 169,648 drivers involved in crashes that took place on two-lane two-way rural roads of Iran over the 3-year period. Table 
Table 1 - Variable description

\begin{tabular}{|c|c|}
\hline Description & Variable \\
\hline Target variable: 1 . No-injury 2. Injury 3. Fatality & Injury severity \\
\hline 1. Male 2. Female & Gender \\
\hline Quantitative & Age \\
\hline 1. Used 2. Not used 3. Unknown & Seat belt \\
\hline $\begin{array}{l}\text { 1. Following too closely } 2 \text {. Ignoring proper lateral distance } 3 \text {. Ignoring right of way } \\
\text { 4. Inattention to traffic ahead } 5 \text {. Inability to drive } 6 \text {. Failure to control the vehicle } \\
\text { 7. Speeding } 9 \text {. Improper overtaking } 11 \text {. Straying to the right } 13 \text {. Improper turning } \\
\text { 14. Crossing prohibited place } 15 \text {. Driving on the wrong side of the road } 16 \text {. Improper } \\
\text { backing } 17 \text {. Vehicle defect } 19 \text {. Swerving } 20 \text {. Pedestrian violation } 22 \text {. Improper pack- } \\
\text { ing } 23 \text {. Improper towing } 24 \text {. Red light running } 25 \text {. Turning in no-turn zone } 26 \text {. Other }\end{array}$ & Cause of crash* \\
\hline $\begin{array}{l}\text { 1. Collision with motorcycle/bicycle } 2 \text {. Two-vehicle collision } 3 \text {. Multi-ve- } \\
\text { hicle collision } 4 \text {. Collision with pedestrian } 5 \text {. Collision with animal } 6 \text {. } \\
\text { Fixed object collision } 7 \text {. Overturn } 8 \text {. Fire/Explosion 11. Other }\end{array}$ & Collision Type** \\
\hline $\begin{array}{l}\text { 1. Auto 2. Mini bus 3. Bus 4. Pickup 5. Light truck 6. Truck 7. Ambulance } \\
\text { 8.Truck with trailer 9. Motorcycle 10. Bicycle 11. Agricultural vehicles } 12 . \\
\text { Highway const. equipment 13. Fire truck 14. Police car 15. Other }\end{array}$ & Vehicle Type $* * *$ \\
\hline 1. Segment 2.Intersection 3. Bridge 4. Tunnel 5. Roundabout 6. Other & Location Type \\
\hline 1. Daylight 2. Dark 3. Dusk/Dawn & Lighting Condition \\
\hline 1. Clear 2. Fog 3. Rain 4. Snow 5. Stormy 6. Cloudy 7. Dusty & Weather Condition \\
\hline 1. Dry 2. Wet 3. Icy 4. Gravel/Sand 5. Slush/Mud 6. Standing oil 7. Other & Road Surface Condition \\
\hline 1. On roadway 2. On Shoulder 3. In median 4. On roadside 5. Outside roadway 6. Other & Occurrence \\
\hline 1. None 2. Stabilized gravel 3. Paved & Shoulder Type \\
\hline Quantitative & Shoulder Width \\
\hline
\end{tabular}

* Cases No. 8, 10, 12, 18 and 21 are not in the dataset.

** Cases No. 9 and 10 were related to motorcycles and pedestrian collision, and were thus eliminated, since the study concerns motor vehicles.

${ }^{* *}$ Cases No. 9 and 10 were motorcycles and bicycles, and were thus eliminated, since the study concerns motor vehicles.

3 provides a summary of injury severity distributions by some key variables.

\section{RESULTS AND DISCUSSION}

Table 2 indicates the relative variable importance computed for the 13 independent variables.

Seat belt turned out to be the most important variable, such that it is about 6 times more important than the second variable, and 90 times than the third one. It indicates that there is more probability for a driver who has not used seat belt to get involved in a more severe injury. This result was also pointed out in some previous studies [12, 16-19] and shows the necessity of seat belt usage being mandatory.

The second important variable is the cause of crash, which confirms the study of Al-Ghamdi [8] in Saudi Arabia, where the cause of crash was recognized as the important factor in increasing crash severity. This research reveals that for two-lane two-way rural roads, improper overtaking and speeding are the serious causes of increasing injury severity, and since overtaking takes place by using the opposite lane, it results in more severe injuries and more lives lost.
Table 2 - Relative importance of variables

\begin{tabular}{||l|l||}
\hline \multicolumn{1}{|c|}{ VIM } & \multicolumn{1}{|c|}{ Independent variable } \\
\hline \hline 0.8214 & Seat belt \\
\hline 0.1484 & Cause of crash \\
\hline 0.0088 & Collision type \\
\hline 0.0029 & Vehicle type \\
\hline 0.0023 & Weather condition \\
\hline 0.0023 & Age \\
\hline 0.0023 & Shoulder type \\
\hline 0.0023 & Shoulder width \\
\hline 0.0023 & Road surface condition \\
\hline 0.0023 & Lighting condition \\
\hline 0.0023 & Location type \\
\hline 0.0023 & Occurrence \\
\hline 0.0001 & Gender \\
\hline 1.0000 & Sum \\
\hline
\end{tabular}

Constructing passing lanes at required places, and special attention to the police enforcement by help of mobile patrol vehicles, are some of the relatively less costly solutions to this problem. 
A. T. Kashani, A. Shariat-Mohaymany, A. Ranjbari: A Data Mining Approach to Identify Key Factors of Traffic Injury Severity

Table 3 - Summary of distribution of injury severity by key variables

\begin{tabular}{|c|c|c|c|c|c|c|}
\hline \multicolumn{6}{|c|}{ Severity frequency } & \\
\hline \multicolumn{2}{|c|}{ Fatality } & \multicolumn{2}{|c|}{ Injury } & \multicolumn{2}{|c|}{ No injury } & \\
\hline 1,791 & $1.06 \%$ & 11,138 & $6.57 \%$ & 156,719 & $92.38 \%$ & Independent variables \\
\hline & & & & & & Gender \\
\hline 1,782 & $1.06 \%$ & 11,064 & $6.57 \%$ & 155,664 & $92.38 \%$ & Male \\
\hline \multirow[t]{2}{*}{9} & $0.79 \%$ & 74 & $6.50 \%$ & 1,055 & $92.71 \%$ & Female \\
\hline & & & & & & Seat belt \\
\hline 757 & $0.56 \%$ & 5,636 & $4.15 \%$ & 129,522 & $95.30 \%$ & Used \\
\hline \multirow[t]{2}{*}{466} & $5.05 \%$ & 2,432 & $26.33 \%$ & 6,338 & $68.62 \%$ & Not used \\
\hline & & & & & & Cause of crash \\
\hline 916 & $2.23 \%$ & 3,921 & $9.57 \%$ & 36,150 & $88.20 \%$ & Improper overtaking \\
\hline 141 & $1.42 \%$ & 1,238 & $12.51 \%$ & 8,516 & $86.06 \%$ & Speeding \\
\hline \multirow[t]{2}{*}{76} & $0.33 \%$ & 843 & $3.62 \%$ & 22,344 & $96.05 \%$ & Ignoring right of way \\
\hline & & & & & & Collision Type \\
\hline 1,008 & $0.93 \%$ & 5,328 & $4.93 \%$ & 101,644 & $94.13 \%$ & Two-vehicle collision \\
\hline 183 & $1.18 \%$ & 968 & $6.24 \%$ & 14,364 & $92.58 \%$ & Multi-vehicle collision \\
\hline \multirow[t]{2}{*}{34} & $0.59 \%$ & 269 & $4.66 \%$ & 5,474 & $94.76 \%$ & Fixed object collision \\
\hline & & & & & & Location Type \\
\hline 1,529 & $1.06 \%$ & 9,290 & $6.43 \%$ & 133,577 & $92.51 \%$ & Normal \\
\hline 48 & $0.45 \%$ & 497 & $4.66 \%$ & 10,118 & $94.89 \%$ & Intersection \\
\hline \multirow[t]{2}{*}{3} & $0.43 \%$ & 10 & $1.45 \%$ & 677 & $98.12 \%$ & Roundabout \\
\hline & & & & & & Lighting Condition \\
\hline 1,166 & $0.95 \%$ & 7,708 & $6.25 \%$ & 114,402 & $92.80 \%$ & Daylight \\
\hline \multirow[t]{2}{*}{558} & $1.36 \%$ & 3,000 & $7.30 \%$ & 37,563 & $91.35 \%$ & Dark \\
\hline & & & & & & Weather Condition \\
\hline 1,537 & $1.11 \%$ & 9,256 & $6.67 \%$ & 127,922 & $92.22 \%$ & Clear \\
\hline 15 & $0.86 \%$ & 76 & $4.36 \%$ & 1,654 & $94.79 \%$ & Fog \\
\hline \multirow[t]{2}{*}{66} & $0.65 \%$ & 648 & $6.34 \%$ & 9,511 & $93.02 \%$ & Rain \\
\hline & & & & & & Road Surface Condition \\
\hline 1,627 & $1.11 \%$ & 9,885 & $6.76 \%$ & 134,624 & $92.12 \%$ & Dry \\
\hline 107 & $0.68 \%$ & 935 & $5.90 \%$ & 14,800 & $93.42 \%$ & Wet \\
\hline \multirow[t]{2}{*}{43} & $0.62 \%$ & 252 & $3.61 \%$ & 6,676 & $95.77 \%$ & Icy \\
\hline & & & & & & Occurrence \\
\hline 1,423 & $0.96 \%$ & 8,468 & $5.72 \%$ & 138,136 & $93.32 \%$ & On roadway \\
\hline \multirow[t]{2}{*}{156} & $1.85 \%$ & 1,311 & $15.51 \%$ & 6,987 & $82.65 \%$ & On roadside \\
\hline & & & & & & Shoulder Type \\
\hline 333 & $0.99 \%$ & 1,816 & $5.41 \%$ & 31,414 & $93.60 \%$ & Paved \\
\hline 742 & $1.17 \%$ & 4,682 & $7.40 \%$ & 57,866 & $91.43 \%$ & Stabilized gravel \\
\hline
\end{tabular}

As shown in Table 2 the variable importance of the other 11 variables is very low, and they do not have a significant influence on predicting the target variable.

Referring to Breiman [5], in order to develop a CART model, the dataset should be randomly divided into 2 subsets of training and testing. In this study, the percentage of data assigned to the training and testing samples is 70 and 30 , respectively. Table 4 represents the model prediction accuracies, computed by dividing the number of correctly predicted data into the total number of observed data, for both training and testing data.

In comparison to the previous similar studies, the overall accuracy of the model decreased in this study, but the prediction accuracy for fatality class increased significantly (from nearly $0 \%$ to $51.27 \%$ ), which is very significant, since it is the most important class for decision makers. 
A. T. Kashani, A. Shariat-Mohaymany, A. Ranjbari: A Data Mining Approach to Identify Key Factors of Traffic Injury Severity

Table 4 - Prediction accuracy of the model for the three classes

\begin{tabular}{|c|c|c|c|c|}
\hline \multicolumn{2}{|c|}{ Testing data } & \multicolumn{2}{c|}{ Training data } \\
\hline Correctly predicted & Observed severity & Correctly predicted & Observed severity \\
\hline $35,736(75.93 \%)$ & 47,063 & $83,463(76.11 \%)$ & 109,656 & 7,765 \\
\hline $941(27.90 \%)$ & 3,373 & $2,324(29.93 \%)$ & 1,297 & No-injury \\
\hline $244(49.39 \%)$ & 494 & $665(51.27 \%)$ & 118,718 & Fatality \\
\hline $36,921(72.49 \%)$ & 50,930 & $86,452(72.82 \%)$ & Overall \\
\hline
\end{tabular}

\section{CONCLUSION}

Variable importance measure (VIM) is one of the CART method outputs, which may be applied as a criterion to select the variables that have major importance in predicting the target variable.

In this study, the aforesaid measure (VIM) was applied to identify the significant factors influencing injury severity of drivers involved in traffic crashes on twolane two-way rural roads of Iran over a 3-year period.

Considering the large amount of crash data on rural roads of Iran, CART was found to be a suitable approach for this study, since it can deal well with prediction and classification problems when there are lots of independent variables.

The results indicated that seat belt is the most important factor associated with injury severity of traffic crashes, and not using it significantly increases the probability of being injured or killed. The cause of crash turned out to be the second important variable, and the research found improper overtaking and speeding as the most serious causes of increasing injury severity for two-lane two-way rural roads. The construction of passing lanes and intensifying police enforcement by help of mobile patrol vehicles are some of the effective and relatively less costly solutions suggested to deal with these problems.

\section{ACKNOWLEDGMENT}

The authors gratefully acknowledge Mr. Sabbaq and Mr. Mishani from the Information and Technology Department of the Iranian Traffic Police for providing the crash data.

\section{LITERATURE}

[1] F.M.O.I. Forensic Medicine Organization of Iran; Statistical Data, Accidents (in Farsi) 2009 [cited May 31, 2009; Available from: http://www.Imo.ir/?siteid=1\&pageid=1347.

[2] R.M.T.O. I.R. of Iran Road Maintenance \& Transportation Organization; Annual Report (in Farsi). 2008 [cited; available on: http://www.rmto.ir/NewTTO/DynaStat/DynaStatF/.

[3] Mussone, L., Ferrari, A., Oneta, M.: An analysis of urban collisions using an artificial intelligence model,
Accident Analysis \& Prevention, Vol. 31, No. 6, 1999, pp. 705-718

[4] Han, J., Kamber, M.: Data mining: concepts and techniques, Morgan Kaufmann, 2006

[5] Breiman, L.: Classification and regression trees, Chapman \& Hall/CRC, 1998

[6] Singleton, M., Qin, H., Luan, J.: Factors Associated with Higher Levels of Injury Severity in Occupants of Motor Vehicles that were Severely Damaged in Traffic Crashes in Kentucky, 2000-2001, Traffic Injury Prevention, Vol. 5, No. 2, 2004, pp. 144-150

[7] Dissanayake, S., Lu, J.J.: Factors influential in making an injury severity difference to older drivers involved in fixed object - passenger car crashes, Accident analysis and prevention, Vol. 34, No. 5, 2002, pp. 609-618

[8] Al-Ghamdi, A.: Using logistic regression to estimate the influence of accident factors on accident severity, Accident Analysis and Prevention, Vol. 34, No. 6, 2002, pp. 729-741

[9] Hanrahan, R.B., Layde, P.M., et al.: The Association of Driver Age with Traffic Injury Severity in Wisconsin, Traffic Injury Prevention, Vol. 10, No. 4, 2009, pp. 361-367

[10] Kockelman, K., Kweon, Y.: Driver injury severity: An application of ordered probit models, Accident Analysis and Prevention, Vol. 34, No. 3, 2002, pp. 313-322

[11] Abdelwahab, H.T., Abdel-Aty, M.A.: Development of artificial neural network models to predict driver injury severity in traffic accidents at signalized intersections, Transportation Research Record, Vol. 1746, No. 1, 2001, pp. 6-13

[12] Delen, D., Sharda, R., Bessonov, M.: Identifying significant predictors of injury severity in traffic accidents using a series of artificial neural networks, Accident Analysis and Prevention, Vol. 38, No. 3, 2006, pp. 434-444

[13] Chang, L.Y., Wang, H.W.: Analysis of traffic injury severity: An application of non-parametric classification tree techniques, Accident Analysis and Prevention, Vol. 38, No. 5, 2006, pp. 1019-1027

[14] Yan, X., Radwan, E.: Analyses of Rear-End Crashes Based on Classification Tree Models, Traffic Injury Prevention, Vol. 7, No. 3, 2006, pp. 276-282

[15] Pande, A., Abdel-Aty, M.: Assessment of freeway traffic parameters leading to lane-change related collisions, Accident Analysis and Prevention, Vol. 38, No. 5, 2006, pp. $936-948$

[16] Bedard, M., Guyatt, G., et al.: The independent contribution of driver, crash, and vehicle characteristics to driver fatalities, Accident analysis and prevention, Vol. 34, No. 6, 2002, pp. 717 
[17] Kweon, Y., Kockelman, K.: Driver attitudes and choices: Seatbelt use, speed limits, alcohol consumption, and crash histories, $82^{\text {nd }}$ Annual Meeting of Transportation Research Board, Washington DC, 2003

[18] Sohn, S.Y., Shin, H.: Pattern recognition for road traffic accident severity in Korea, Ergonomics, Vol. 44, No. 1, 2001, pp. 107-117
[19] Valent, F., Schiava, F., et al.: Risk factors for fatal road traffic accidents in Udine, Italy, Accident Analysis and Prevention, Vol. 34, No. 1, 2002, pp. 71-84 